\title{
Landy Through the Lens of 'Michael': A Short Essay on One Case Study
}

\section{Professor Phil Jones, University College London, Institute of Education}

\section{Introduction: 'Michael' and Landy}

The 'Case of Michael' is a study written by Robert Landy in 1993. In the specifics of 'Michael' I intend to find a way of talking about Landy's work and some key aspects of its value. I will review the account of practice, arguing for the use of broad and particular frames as a way of analyzing what the Case Study reveals about Landy's work. Though this essay can be read in itself, it will be more meaningful is it is used as an excuse to go back and re-read the Study in ‘Persona and Performance' (1993).

The client, Michael, is described as being twenty seven, from a suburb of Chicago, and as having begun therapy 'because he felt fearful, isolated and lonely a good deal of the time', choosing drama therapy 'because he often used words defensively to avoid feelings, and felt that he could express himself more authentically through a creative process' $(1993,57)$.

The therapist and academic, Landy, had founded the drama therapy programme at New York University (NYU) nine years previously and had brought out 'Drama Therapy: Concepts and Practices' just seven years before writing the study. This was one of his first extended published case studies and I am choosing it as a way of returning it to the field's attention, and as part of the celebration and discussion of Landy's theory and research in this Journal. My 
approach is to use it as a way in to thinking about his work and to analysing what the study communicates, in a microcosm, about some important facets of his contribution to knowledge.

The writing in 'Michael' is a constant Landy signature. By this I mean that every sentence and paragraph reflects his identity as therapist, improviser, actor-director, dramaturg, theorist, storyteller, teacher and researcher. The signature is also expressed through what I am going to call frames that help us see what Landy wants us to learn about drama as therapy. From the first encounter with Michael to the last moments of the study we are, as readers, learners and colleagues, invited into these frames. I think they can usefully be seen as broad and particular frames.

By broad frame I mean one that concerns wide, generic insights into role and drama therapy: offering a nexus of theory and method. My analysis of the study will show how the work is animated by Landy's conception of, and engagement with, role as therapy. This frame will help us see, within 'Michael', the wider, more explicit aspects of Landy's intentions for the field.

The particular frame is a lesson in itself, and though this 'lesson' it is never explicitly stated by Landy, I hope to use the frame to help us see, as clearly as a sharp ray of light, another message for the field. This frame refers to the ways in which Landy and Michael's work together is, in an important sense, absolutely particular and cannot be generalized.

\section{Two examples of Michael}


I've chosen the two following samples from 'Case of Michael' to illustrate Landy at work and to examine the presence in each of both of these frames.

\section{Example 1 (Landy 1993, 64-5)}

Michael creates a role with Landy: 'Black Rage'. He has talked about being unfocused and angry. Landy's response is to ask him to 'find a focus' for his anger and a role 'emerges' from this conversation $(1993,64)$. The client then creates a story with the role. The named 'Black Rage' is brought out of its latency into the manifest existence of enacted role and imaginary contact with Michael and his family. Michael illustrates this in his quoted comment:

Black Rage, an "it", came with my grandfather and was passed on to my father. I inherit it from my father. So does my brother and little sister' $(1993,64)$.

The role's presence is further linked to the next generation: his pregnant sister and the client 'tell' the baby about 'Black Rage'. Landy invites Michael to close his eyes and visualize a time earlier in the day when he experienced anger, locating it within a role interaction. This is accompanied by the following commentary from Landy:

He recognized the presence of Black Rage in his upper body-shoulders, neck, jaw. It was painful. I asked him to re-experience the pain, then wrestle it off and throw it into the chair in front of him. He did so powerfully, then addressed Black Rage:

I want to get rid of you. Leave me alone! 
I took on the role of Black Rage:

You need me. You don't really want me to go.

We reversed roles. As Black Rage, Michael said;

The only way to let me go is through love and the letting in of real feelings.

Michael then cries 'openly, attempting to let go of the demon crouched on his shoulders' (1993, 64).

This is followed by reflection. Michael is reported discussing daily dynamics in relation to the 'cycle of anger', seen in terms of male and female roles and emotions. Landy says that the 'Black Rage' is a role type - 'a kind of demon' $(1993,65)$.

\section{Example 2 (Landy 1993, 74-6)}

Landy talks of a 'figure' brought into the session from Michael's dream: Patty. Landy has asked the client to play himself in relation to Patty and, after Michael has stroked the air, Landy takes off his own sweater, 'bunched it up, and gave it to him' $(1993,74)$. Michael is described as holding it tenderly and saying 'Don't cry,' to Patty - which Landy interprets as an 'abused silenced child, who is the object of the Black Rage', with the other as protector and 'nurturing father, mature adult' $(1993,75)$. 
Landy comments:

Michael's style of enactment was balanced, evoking deep feeling as well as reflection. After crying, he said:

I feel a great sense of relief and clarity. I know Patty very well. She lives inside me.

I found myself full of feeling as never before with Michael. The image of the ring came to mind. Was this the connection, the bond that could be finally be dramatized directly, with father and child playing out their appropriate roles - the father as strong dependable, loving; the child as dependent, imperfect, vulnerable? $(1993,75)$.

Landy and Michael go on to talk of the meaning of the roles and 'the tasks that remained' $(1993,75)$. This occurs within a process of reflection, further described in the following manner:

The major child role types were now visible and nameable: the innocent; Baby Blue; the idealist; Bo; the victim; Patty; the warrior, Billy. In the identification of theses roles, Michael came to see certain parts of himself that were not clear before. In working through the roles he was attempting to find a balance among them, so that any one would not usurp too much power from his role system. That balance would come not only through the child roles, but also through Julian (the lawyer), Judge, Black Rage, and other father roles and feminine roles already discovered butyet to be integrated...I had become very human to him, both therapist and father, both accepting critic and critical judge. I could now be addressed directly and looked in the eyes $(1993,76)$. 


\section{Review of Examples 1 and 2: Broad Frame}

Within the Case Study we are shown processes that are in a broad frame and that I will argue are reflective and illustrative of what has become known as the 'role method'. This frame is one that helps us perceive within the study what is generally applicable across drama therapy in a variety of contexts. Looked at in this way, 'Michael' displays what I am calling the 'broad frame' of the role method: the life brought into a therapeutic encounter by Landy's ways of conceiving of, and engaging with, role as therapy.

In 'Michael,' we can see reflections of role as a concept and language to analyze and communicate aspects of human experience: as a way of client and therapist creatively expressing and exploring past and present material within drama therapy. The Case Study asserts, for example, that in working through roles, Michael is attempting to find 'balance' among them, so that 'any one would not usurp too much power from his role system' (1993, 76). Beneath the surface of such a brief and succinct conclusion, we can see a strong infrastructure of theory and method which Landy has produced with, and for, the field over many years. 'Michael' illustrates the ways in which Landy sees the transformative base of drama as therapy and the study exemplifies some of the contributions he has made to helping us articulate what was, previously, known intuitively whilst not being so effectively expressed. We see, for example, the ways in which change is enabled and energized by the interaction between empathy and 'distancing'; the rich possibilities of the naming of 
experienced roles, the creation of new roles and of role variety and possibility; the dynamic between the client's everyday ways of being and the creation, exploration and working through of fictional roles; of the therapeutic possibilities of reflection; and the values of an ongoing relationship with a creative, dramatically empowered therapist.

These are revealed in the ways Landy talks about Michael's process over time as the therapy progresses and the healing occurs. Michael's individual agency is prioritized within this: it is not something imposed by the therapist. Michael has created the roles and dynamics specific to his life and engagement with Landy. At the same time, Landy shows us broader principles in action. In the review of the work in Example 2, as 'major child role types were now visible and nameable' $(1993,76)$, for example, Landy shows us a particular rhythm and set of interactions. The review with Michael demonstrates three 'levels' in interaction as a principle: that fantasy roles, real life roles and the client-therapist role relationship can create a dynamic between them, and can combine to enable change. Within the example text, images of visibility and being able to identify and to see are much used by Landy in communicating the work. Firstly the therapy in its dramatic activities, space and relationships enable role types to be 'visible', then Michael 'sees' more clearly than before as he engages with the roles, and Landy as therapist comes into focus - as the client can be 'looked in the eyes' $(1993,76)$. This drawing on imagery about visibility is accompanied by certain kinds of interaction. I would suggest that the text about the review shows us how Landy considers that seeing and identifying are positioned as powerful connected actions - enabling change. This is achieved by roles becoming 'nameable', which can occur as something is made clearer or explicit, and by 'working' $(1993,76)$ with processes such as role-playing and reflection. One of the main qualities of Landy's attention and work is that it identifies and names specifics and likes precision of attention brought about by a type of focusing, even of a kind of isolating, 
categorizing, listing quality. Landy sees these actions as being connected to replacing invisibility and imbalance with presence and balance. We can see this process occurring constantly within the Case Study as a whole. One example of such a commentary is from the early stages of the therapy:

In this session the roles of father and son coexisted on three different levels: the theatrical level of Bo and Julian; the therapeutic level of client and therapist; and the everyday level of Michael and his father $(1993,69)$.

In such a moment, Landy makes overt the ways in which different domains of Michael's life are brought into a positive relation through the traffic, or interaction, which drama therapy enables. By this I mean that he is showing us how change is enabled through the ways the different 'levels' can be created, and that the interaction between the levels can facilitate change where it is needed. Material that might be experienced as un-named or untouchable, 'stuck' or problematic when framed as son and father, can be freed up to being seen and explored when created in the drama therapy space expressed as roles such as 'Bo' and 'Julian' or reworked within the role relationship of therapist and client. We can see in this instance of 'Michael' these broad drama therapy principles: how client and therapist experience and create positive change through working with different 'levels' of role simultaneously and separately.

Part of what is crucial to an understanding of this broader perspective, however, is that the attention to role, when looked at more carefully in Landy's work with Michael, is deeply part of a wider more complex matrix. It might be tempting to look at Examples 1 and 2 and the Case Study as a whole and to think that the frequency with which Landy uses the term to 
represent that 'role' is the total sum of how Landy places Michael's experience of change. However, that is to misconstrue what Landy is about in 'Michael' and, perhaps, in his work more generally. It is to mistake what is foregrounded for what is present in the whole picture, or on the whole stage of the therapy. The following are two extracts elsewhere in the Case Study to illustrate this:

In preparing for the role of Mickey, Michael imagined that is brother was trapped in the minefield and he must say him. While at home for Thanksgiving, he even asked Steve to scream on a tape recorder to provide a more heightened sense of emotional reality....(1993, 98-9)

We spoke of the ways in which Michael could play the ridiculous quality of Lomov without feeling the sting of his mothers brand of humor. We then spoke of the function of the Lomov role, which Michael recognized as pointing out to an audience the silliness that comes from self pity $(1993,84)$.

One of the temptations of reading and thinking about Landy is to assert that it is only about role. This is to misunderstand his work both conceptually and practically. Role in Landy is not the whole: it is the central element but only within a greater matrix of interdisciplinary processes. In the above quotes, for example, we can see how Michael undertakes research for his performance by tape recording a real person in his life to bring into his therapeutic performance. In the reflection process about Lomov. Michael and Landy engage in the process of critiquing and analyzing performance, Landy notes that this acknowledges the part of theatre process that involves the 'critic' $(1993,83)$. This is a sample of the interdisciplinary matrix which role, in Landy's work, is a part of. Here role connects to concepts and practices such as performance research and the process of audience and critic within theatre. A 
different illustration of this can be seen in how, reflecting on the past with Michael, Landy notes that humor 'served a healing process. He liked to play and kid with his siblings' (1993, 84). Theories of the therapeutic function of play are used by Landy here. He analyses Michael's family dynamic using play theory. Within this framework, elements of reality that might be hard or distressing to express directly, are engaged with through the form of play. This involves the creation of a playful re-experience that enables expression and communication. Landy and Michael refer to his family by drawing a contrast between laughter and humor that is used to hurt or 'ridicule' and healing play that is created between Michael and his siblings. Here role is situated in dialogue with theories of play and the practical experience of Michael's playing to both enhance Landy's understanding of how change is occurring and to create processes and experiences within the drama therapy.

Role is the process and language which creates the forms of expression, communication, exploration and meaning making within the drama therapy. Role becomes a spectrum of being - creating interaction and relationship between Michael when he is within the therapy space and when he is in his life outside the space. However, in the Case Study the broad perspective on drama as therapy is more complex, and the process of change is richer, than an analysis that relies on role purely. Within the account we see the ways in which an interdisciplinary dynamic is created: script creation, audience, directing, stage setting, storytelling, play, movement and embodiment are being reframed in the way they are understood and made available to both Landy and Michael. This reframing is common to much drama therapy literature. However, through the writing about Michael we can see the specific ways this occurs and helps see role within the true living matrix of the interactions between broader dramatic, theatre and play processes and of the work of various theories of therapy, witnessed in the ways Landy, in the Case Study, draws on psychoanalytic 'musings' 
on Hamlet $(1993,69)$ or on attachment $(1993,103)$. It is this matrix, whereby role is animated by a diversity of cultural and psychological interconnections within the frame of 'drama therapy', which is at the heart of Landy's lessons for us from a broad perspective.

\section{Review of Examples 1 and 2: Individuality of Michael, individuality of Landy - Irreplicable and unique}

By the 'irreplicability' of Michael, I mean the ways in which the Case Study is suffused by a precision of attention to him: both in the way it is written but, most importantly, in the ways the details of Michael's life and lived experience are responded to within the drama therapy encounter. The following analysis of aims to make explicit the layer of writing that- I think - is intended to communicate Landy's template for the ways in which a drama therapist needs to be alert to the individuality of the client they are working with and to their own individuality as a therapist. The Case Study is exactly and precisely to do with client Michael in ways that cannot be simply replicated, and it is exactly and precisely to do with therapist Landy in ways that also cannot be replicated.

\section{The individual Michael}

We are shown the particularity and individuality of the client, in the precision and fine grain of the account of Michael's life experiences, thoughts, feelings and his creativity. This is not an accident but an important aspect of the study: its style communicates crucial aspects about its concepts and practices. A key part of the way Landy shows role here is to demonstrate, in the way he writes, attention to 'Michael' as a unique, in the moment encounter. By particular attention here I mean that Landy wants to show us the importance of the specific details of 
Michael's verbal and physical communication: in Examples 1 and 2, for example, through the creation of a unique combination of memories, associations, creativity and perceptions to form 'Black Rage'.

Landy makes in the moment decisions as responses to this specific, individuality in 'Michael'. One sample can be seen in Example 1: the decision to take his client's feeling of unfocused anger with an invitation to enter into the pain, to wrestle and throw it into a chair, and then for Landy as therapist to take on a particular, newly created role and offer words about need. Another can be seen in Example 2, within Landy's in-the-moment decision to take off his own sweater and in the particularly chosen act of bunching to give it to Michael. Here he shows us the importance of such spontaneity, responding to specific situations and expressions offered by Michael.

\section{The individual Landy}

The other particular perspective is that which concerns Landy himself. Within the Case Study I will now show how he demonstrates the ways in which he as a specific, individual brings his own uniqueness into the process. I suggest this offers Landy's template for us to see this important aspect of the drama therapist's nature and work.

Landy's own individuality is expressed and reflected within the ways in the moment decisions and actions are emphasized within the account, as noted in the previous section. We see him, as an individual in an another way, though: making chains of association, drawing on his very own specific cultural experiences and events, which are brought to the encounter. The following is part of the rationale Landy brings shortly after he has entered into the chair in the 
first example and asserted, as 'Black Rage', that Michael needs him and doesn't really want to let go:

'It appears to be born of the marriage of fear and anger...it bears some resemblance to the feminine Eumenides or Furies in Greek drama, who plague such masculine characters as the rigid, authoritarian Pentheus in The Bacchae and the guilt ridden Orestes. The legacy of Black Rage is that seen in the classic revenge tragedies and contemporary revenge films pitting blood relatives against ne another. Black rage as Michel conceived it, can be appeased through love and the authentic expression of feeling...Perhaps the primary function of Black rage, like that of the Furies and other dramatic demons, is to demand a place in the human psyche for that which is irrational, fearful and rageful $(1993,65)$.

Though Landy doesn't say this, or make the connection directly in the Case Study, I want to draw attention here to the ways in which he wants to show us his own, individual knowledge of specific artifacts and, within the way of working demonstrated in the Case Study, his own unique awareness. The connections about the function of 'Black Rage' for Michael are created through Landy's own personal associations. The account aims, I think, to helps us see that this kind of individual knowledge - of Landy's reading and seeing dramas in his own life - informs his decision to take up and use the role of 'Black Rage'. The insights from his experience of Greek classical drama or of contemporary revenge films are shown by Landy to help him make a decision on Michael's work and how he will act as therapist. His reflections on the nature of the Eumenedies -to assert the need for the presence of the irrational, fearful and rageful - is a direct influence on his decisions to bringing the role of 'Black Rage' out of Michael's body, into the chair and then to embody it himself with words, quoted above, that echo this interpretation: 'You need me. You don't really want me to go'. 
In this way, I would argue, Landy is demonstrating how he is using his own individual cultural history and experience to create contact and therapeutic change with Michael. He is not trying to be neutral, or to intervene in a standardized way: the creativity of his response is fueled in part by his own individuality as a therapist. I interpret a part of this as Landy affirming the value of the individual knowledge, spontaneity and creativity of the drama therapist.

Another aspect of this individuality concerns the ways in which individual clients and therapists change each other through the interactions between their identities and experiences within the therapy. The therapy process in 'Michael' is animated by an exchange brought about by client and therapist meeting each other as individuals and being involved in a creative exchange over time. We are shown therapist knowledge, for example, in the act of changing, evolving, even within this one client example. Just as Landy brings his experience, knowledge and creativity into the spontaneity of the experience to the value and development of the client, so the client is shown as having an impact on Landy's knowledge, perceptions, experiences and insights into role. Landy shows us how he changes as we accompany him in the narrative of the Case Study:

I thought of a diminutive Samuel Beckett play, Come and Go (1968) an abstract piece involving three women who engage in esoteric rituals...at the end, all hold hands as ne of the women says 'I can feel the rings' I once directed the play and had some sense of the bonds - racial, feminine ties. But none of these names fully satisfied me....is it a transitional object that helps beauty break with the father and move toward the lover? Or does it point toward the triangulation of fatherdaughter-lover... a psychological dilemma close o the spirit of Freud's Oedipus complex? I also wondered whether this oedipal triangulation was a source of Michael's malaise. $(1993,59)$ 
Here the therapist as an individual is shown in the act of changing: his cultural and psychological awareness is being amended by the specific encounter with the specific client. He is showing us how he takes his own cultural knowledge of a Beckett play, his memory of a performance and experience of directing it along with knowledge of Winnicott and Freud to create a unique interaction with Michael's psychic resonances to the ring in Beauty and the Beast. In this extract from the Case Study we can see how Landy's awareness of Freud and Winnicott and of Beckett is being changed and developed by Michael. The new associations for Landy look afresh at the 'triangulation' $(1993,59)$ in a series of questions. His style - showing us himself asking questions and trying out possible formulations, takes us into his thinking in action and the emergence of possible directions and new connections. The teacher in Landy is showing us - through the act of reading the text quoted above - his individual trains of thought and his creating, testing and accepting or rejecting of new possible connections between classical Greek drama, twentieth century experimental theatre, his own memories, Freudian theory and Michael's associations and role experience from Beauty and the Beast.

This is not commented on directly by Landy - but it affects us as we read the study and my interpretation here aims to make this explicit: as something that stands for a strand within much of Landy's work. Here Landy reveals the peculiarness of himself - and this is brought into the Case Study and communicated to us as valuable and as essential to the potency of the drama therapy.

This is not a therapeutic process offered as a generic treatment, where replication is allied to efficacy: rather, it illustrates the rich value of in-the-moment, individual responses held in creative dialogue with broader understandings of therapeutic change in drama therapy. 


\section{Conclusion}

In 'Michael' the drama therapy space is identified by Landy as having particular characteristics and processes for, as I have shown, both client and therapist. Landy uses the metaphor of a journey, the client 'arrives' and the therapist ends their work with the individual. However, at the close of the Case Study, this is immediately contrasted with a seeming paradox - that the end of the therapy, the 'arrival', is also a stage that must not become fixed:

Before arriving at the heroic place of survivor or victor, Michael needed to work through the ways he victimized himself by holding onto passive, fearful, and depressive roles within...If one treats a transformed role system like a closed book, it may revert back to its previous hold on one's wellbeing $(1993,110)$.

Michael's and Landy's identities in 'Case of Michael' are shown as reflexive and both client's and therapist's self hood is positioned as a collection of interdependent and interacting role identities and relations. Health for both is seen as a particular set of relations and a capacity to be aware of, and to engage actively, with these role dynamics. In the last stage of the Case Study and his commentary on Michael, demonstrated in the above quote, Landy shows us that something that is learned or altered in the client's and therapist's ways of being needs to continue as a living, changing process. This essay has illuminated a number of facets within this learning and process. 
'Michael' is research and it speaks to us of a rich, in depth qualitative way of approaching enquiry in drama therapy. 'Michael' offers a valuable template for an approach in Case Study detailed, thorough data from the client and a lucid and reflexive self are placed jointly at the core of the enquiry. We have Michael's testimony as shaped by the therapeutic encounter and by the therapist researcher's sense of what matters. It speaks of two men in a particular time and a particular place, who meet in a psychological and cultural space located by specific experiences of personal history and in-the-moment flashes of interaction; of Greek theatre; Western European fairytales and of Freud and Winnicott. At the same time it resonates with dynamics at work that are outside of those temporal locations: of how Landy sees the creation of roles, fictions, narratives, dreams and how contact between humans can try and help, to enter into imaginative, creative spaces guided by understandings of how damage might be caused and repaired or how growth can be imagined and pursued through creativity and relationships. As this essay has shown, in 'Case of Michael' we, as readers, students and colleagues learn about the broad perspectives of Landy's concepts and practices, but also about the value of the particular, individual nature of attention for the drama therapy encounter between client and therapist.

\section{Reference}

Landy, R.J. (1993) 'The Case of Michael,' Persona and Performance: The Meaning of Role in Drama, Therapy, and Everyday Life, London: The Guildford Press. 